\title{
8
}

\section{REFORMA DO ENSINO MÉDIO NO BRASIL EM 2017: ASPECTOS PEDAGÓGICOS E FORMATIVOS*}

\author{
José Romero Machado Gontijo \\ Cílson César Fagiani
}

\section{Introdução}

A Reforma do Ensino Médio (BRASIL, 2017a) foi iniciada através de um "Projeto Piloto", cuja proposta foi a oferta em algumas escolas públicas estaduais de Ensino Médio, o curso Técnico Profissionalizante de Nível Médio em tempo integral e integrado com o Ensino Médio Básico, de acordo com a Portaria $n^{\circ}$ 727, de 13 de junho de 2017 (BRASIL, 2017b).

Um dos fatores relevantes que sustenta o descaso com a Educação está diretamente vinculado ao controle da educação pelo Governo Federal Brasileiro, atuando de forma monopolizada, radical e de cunho capitalista, visando formar o "homem produtivo" e não o "homem social" atendendo as necessidades produtivas, tendo a força de trabalho como meio de produção, do mercado capitalista exploratório.

Antes da reforma, o currículo do Ensino Médio abarcava 13 disciplinas obrigatórias nos três anos, com carga horaria mínima anual de 800 horas. A reforma curricular se constitui de uma parte obrigatória (conteúdo da BNCC) e por outra parte opcional (os itinerários formativos), sendo obrigatório o Português e a Matemática nos três anos. A carga horária mínima anual será ampliada de forma progressiva para 1.400 horas, devendo os sistemas de ensino oferecerem, no prazo máximo de cinco anos, pelo menos 1000 horas anuais de carga horária, a partir de 2 de março de 2017, e deverá utilizar no máximo 600 horas anuais para a BNCC.

Os itinerários formativos serão cinco: Linguagens e suas Tecnologias, Matemática e suas Tecnologias, Ciências da Natureza e suas Tecnologias, Ciências Humanas e Sociais aplicadas e Ensino Técnico Profissionalizante. Dependendo da composição do curso escolhido pelo estudante, haverá menor ou maior ênfase em determinadas disciplinas, ou seja, alguns desses itinerários não serão ofertados, quem optar por linguagens, por exemplo, terá mais horasaulas de Português do que de Matemática. As escolas, porém, não serão obrigadas a ofertar as cinco áreas, de forma que o estudante, dependendo da

${ }^{*}$ DOI - 10.29388/978-65-86678-49-9-0-f.135-152 
escolha, pode ser obrigado a mudar de instituição ou optar por uma ofertada no estabelecimento que estuda.

Segundo o Ministério da Educação (BRASIL, 2017c), as avaliações serão cobradas conforme os conteúdos curriculares da parte comum da BNCC, buscando avaliar habilidades a cada etapa da escolarização, além de orientar a elaboração de itens em testes e provas, bem como a pontuação para as escalas de proficiência que definem o que e quanto o educando realiza no contexto da avaliação. Sobre proficiência, convém observar:

A matriz de competências e habilidades que estrutura o Encceja considera, simultaneamente, as competências relativas às áreas de conhecimento e as que expressam as possibilidades cognitivas de jovens e adultos de compreender e realizar tarefas relacionadas a essas áreas (competências do sujeito). As competências do sujeito são eixos cognitivos que, associados às competências apresentadas nas disciplinas e áreas do conhecimento do Ensino Fundamental e Médio, referem-se ao domínio de linguagens, compreensão de fenômenos, enfrentamento e resolução de situações-problema, capacidade de argumentação e elaboração de propostas. Dessas interações resultam, em cada área, habilidades que serão avaliadas por meio de questões objetivas (múltipla escolha) e pela produção de um texto (redação) (BRASIL, 2017c, p. 01).

De acordo com o texto acima, as avaliações do Ensino Médio devem seguir os conteúdos curriculares comuns da BNCC. O Exame Nacional do Ensino Médio (ENEM), realizado pelo Governo Federal e crescente mecanismo de acesso ao Ensino Superior, também irá se adaptar ao novo currículo, porém não contemplará a eminente eliminação de disciplinas na formação de jovens e adultos que optarem por um curso profissionalizante, o que não ocorrerá, por outro lado, com o educando que optar por estudar o tempo integral os conteúdos da BNCC e itinerários não profissionalizantes, assim terão maiores condições de acesso aos cursos superiores.

Para entender as características autoritárias impostas pela reforma, é necessário saber o processo de formulação e os trabalhos realizados em prol da elaboração das diretrizes curriculares presentes na BNCC.

Assim, de acordo com Ruiz (2017), ex-reitor da UNB e ex-secretário da Educação do DF, a Reforma do Ensino Médio foi iniciada em 2010, com a discussão sobre a atualização das Diretrizes Curriculares Nacionais do Ensino Médio, homologadas em 1998. As novas Diretrizes foram homologadas pelo MEC, em 2012. Durante a discussão, foram realizadas audiências públicas com diversas entidades de professores, alunos, universidades, ONGs, dirigentes de todas as esferas públicas, sindicatos e representantes do Parlamento, da área da Educação. Foi um esforço gigantesco de todos os participantes para chegar a 
um modelo que contemplasse as diversas visões para o Ensino Médio. Houve muito diálogo durante o tempo que duraram as discussões.

Uma das recomendações citadas nas Diretrizes Curriculares Nacionais do Ensino Médio, encaminhada ao MEC, foi a da construção da Base Nacional Comum Curricular BNCC, reforçando a recomendação já existente nas Diretrizes Curriculares Nacionais da Educação Básica.

Em 2012, o MEC encaminhou ao Conselho Nacional de Educação CNE a segunda versão da Base Nacional Comum Curricular, amplamente divulgada e discutida pela internet, muitas sugestões foram apresentadas e grande parte delas consolidadas pela $\mathrm{UnB}$, com auxílio das comissões criadas pelo MEC para a elaboração da BNCC.

De acordo com Ruiz (2017), o processo da reforma foi atropelado em 2013, quando ocorreu a criação de uma Comissão Especial da Câmara Federal para reformar o Ensino Médio. A proposta dessa Comissão, formada por dissidentes em alguns pontos da proposta discutida com a sociedade, modificou em inúmeros pontos a versão aprovada pelo CNE e homologada pelo MEC em 2012, repassando uma nova versão da BNCC ao MEC, desfazendo todo diálogo e contribuição ocorrido com a sociedade e a comunidade escolar e intelectual.

$\mathrm{Na}$ realidade, o que houve foi a inviabilização da reforma em andamento, para introduzir uma reforma que contempla, pontualmente e facilita, a gestão dos dirigentes Estaduais e Municipais, isto é, secretários Estaduais e Municipais de educação, sem a menor preocupação com os estudantes, professores, pais e sociedade.

Assim, fica explícito o descaso com o compromisso de ofertar uma educação de qualidade ao analisar a Lei 13.415/2017 (BRASIL, 2017a), que visa suprir a questão da falta de professores principalmente com o aumento da carga horária para período integral nos itinerários de formação profissional, autorizando a contratação de profissionais não habilitados na área específica da disciplina, porém, que tenham "notório saber" em relação ao tema. Cabe à Secretaria de Educação de cada estado definir o que é "notório saber" e quem estará autorizado a lecionar no Ensino Médio. No entanto, o currículo de formação desses profissionais não contempla a formação pedagógica, desvalorizando a qualidade do processo ensino-aprendizagem e afrontando claramente a categoria dos Professores, pois mostra o descaso e a desvalorização desses profissionais (BRASIL, 2017a).

O que de fato se propõe, com essa reforma, é que algumas escolas ofertem algum itinerário, conforme os professores existentes na instituição, o que elimina a possibilidade de escolha, por parte do aluno. $\mathrm{O}$ aluno matriculado numa determinada escola se matriculará nas disciplinas que a escola oferte, sem chance de opção. A opção é para os dirigentes, pois eles oferecerão os 
itinerários possíveis, nas escolas viáveis e com os professores que tenham à disposição da instituição.

A opção pelos itinerários significa antecipar para o Ensino Médio uma das causas da evasão de estudantes nas universidades públicas, qual seja a opção errada na escolha da carreira no exame de ingresso. É muita responsabilidade para os jovens que estão em plena adolescência. Os jovens erram muito ao escolher a futura carreira no ingresso à universidade, o que poderá ocorrer possivelmente com a Reforma. Dessa forma, o erro será potencializado.

Acerca da temática dos itinerários, Teixeira (2017) destaca:

Define itinerários formativos como os caminhos possíveis que um estudante pode seguir durante sua trajetória acadêmica e de formação, como o conjunto de etapas que compõem a organização da oferta da Educação Profissional pela instituição de Educação Profissional e Tecnológica, no âmbito de um determinado eixo tecnológico (TEIXEIRA, 2017, p. 01).

Para Lima Filho (2017, apud TEIXEIRA, 2017, p. 1637), a reforma do Ensino Médio preconiza a redução dos gastos públicos, com a redução do ingresso de alunos ao Ensino Superior, além de encaminhar precocemente para o mercado de trabalho uma grande parte da classe jovem trabalhadora. Assim, salienta:

A reforma do ensino médio, ao instituir o itinerário de formação técnicoprofissional suprime o caráter que a LDB trazia do ensino médio como etapa final da educação básica. A precoce formação profissional técnica e a inserção do estudante no mundo de trabalho tem como objetivo diminuir a demanda pela educação superior. Além disto, a falta de condições estruturais- equipamentos, laboratórios, espaços de trabalho no caso dos itinerários na educação profissional, são elementos que inviabilizam a proposta, principalmente ao se considerar o quadro contraditório em que o mesmo contexto político acaba de aprovar por 20 anos o congelamento dos investimentos (TEIXEIRA, 2017, p. 16037).

O Decreto 2.208/97 BRASIL (1997) do Presidente FHC, permitia o acesso à Educação Profissional somente a partir da conclusão do Ensino Médio ou de forma concomitante, a partir do Segundo Ano. Isso foi fonte de atrito e de muita animosidade entre Governo Federal e a comunidade da Educação Profissional. A pacificação só veio em com a edição do Decreto 5.154 (BRASIL, 2004), do Presidente Lula, permitindo como opção a integração entre o Ensino Médio e a Educação Profissional. 
A questão mais séria no itinerário da Educação Profissional é a segregação que se faz desses estudantes. A eles, é permitido, caso façam a escolha do itinerário de formação profissional, obter o diploma de técnico, mas não estarão preparados para ingressar nas universidades, porque ficaram defasados ao escolher ou mesmo por ter tido apenas conhecimento do itinerário profissional e não o de Humanas ou de Ciências da Natureza. Para dar continuidade nos estudos e ingressar na universidade, exigirá do estudante do Ensino Médio cursos preparatórios para as avaliações do ENEM, ou fazer outro itinerário para suprir a defasagem de conteúdo curricular, porém destacase que a idade desses jovens já não será a mesma.

Existe uma grande desigualdade na sociedade brasileira, justamente a parcela mais pobre é a que mais frequenta a escola pública. Essas crianças e jovens da escola pública são as que precisam ter uma Base Nacional Comum com todas as disciplinas básicas, que contemplem as suas singularidades, possibilitando uma formação integral, seja nas áreas das Humanas, das Exatas, das Linguagens ou das Ciências da Natureza. Assim, exercer o direto constitucional do acesso a tudo o que é básico, em todas as áreas, e é por esse motivo que é chamada Educação Básica. Se é básica, deve ser igual a todos, em especial aos que mais sofrem com a desigualdade.

\section{Concepções de currículos e aspectos formativos}

Para Freire (1996), no Brasil encontramos constante processo de desvalorização da prática docente em todos os níveis. A pedagogia da autonomia dá subsídios à apreensão da prática docente enquanto dimensão social da formação humana, assumindo postura vigilante contra práticas de desumanização. Para praticar ações humanizadas, é preciso um processo de leitura fatalista da globalização e da ação do capitalismo na formação da desigualdade social, uma reflexão crítica das verdadeiras causas da degradação humana.

Para Machado (2018, p. 13), a educação de qualidade passa por uma boa gestão dos processos pedagógicos da escola, dessa forma, a Gestão Pedagógica se define:

Cuida de gerir a área educativa, da educação escolar no que se refere aos objetivos gerais e específicos para o ensino; as linhas de atuação, em função dos objetivos e do perfil da comunidade e dos alunos; as metas a serem atingidas. Ela ainda preocupa-se com os conteúdos curriculares; acompanha e avalia o rendimento das propostas pedagógicas, dos objetivos e o cumprimento de metas; avalia o desempenho dos alunos, do corpo docente e da equipe escolar como um todo. Suas especificidades devem estar enunciadas no Regimento Escolar e no 
Projeto Pedagógico (também denominado Proposta Pedagógica) da escola e como parte integrante desse temos o Plano Curricular. Tem-se uma expectativa que o Diretor seja o grande articulador da Gestão Pedagógica e o primeiro responsável pelo seu sucesso sempre auxiliado nessa tarefa pela Equipe Pedagógica (Supervisor, Orientador).

Para Saviani (2000), o processo ensino-aprendizagem passa fundamentalmente pelo caminho apontado pelos educadores, sendo os responsáveis diretamente pelo processo de direcionamento da formação e construção do conhecimento, onde os educandos precisam ser provocados e estimulados nas suas habilidades cognitivas, como identificar, diferenciar, relacionar e contextualizar. Dessa forma, é iniciado um mecanismo de aquisição de informações dentro de um contexto interligado gerando o conhecimento e a formação integral do discente.

Acerca da prática docente que estimule as habilidades do discente, Freire (1996, p. 14) explica:

O educador democrático não pode negar-se o dever de, na sua prática docente, reforçar a capacidade crítica do educando, sua curiosidade, sua insubmissão. Uma de suas tarefas primordiais é trabalhar com os educandos a rigorosidade metódica com que devem se "aproximar" dos objetos cognoscíveis.

Assim como em "Pedagogia da Libertação", quem liberta só pode libertar a si próprio, na Pedagogia da Autonomia, somente o discente pode adquirir, ou seja, construir sua própria autonomia na formação. Assim, o docente passa a ser apenas um mediador do conhecimento que também aprende ao ensinar. Dentro desse pensamento, Freire (1996, p. 13) observa:

Se, na experiência de minha formação, que deve ser permanente, começo por aceitar que o formador é o sujeito em relação a quem me considero o objeto, que ele é o sujeito que me forma e eu, o objeto por ele formado, me considero como um paciente que recebe os conhecimentos - conteúdosacumulados pelo sujeito que sabe e que são a mim transferidos. Nesta forma de compreender e de viver o processo formador, eu, objeto agora, terei a possibilidade, amanhã, de me tornar o falso sujeito da "formação" do futuro objeto de meu ato formador. É preciso que, pelo contrário, desde os começos do processo, vá ficando cada vez mais claro que, embora diferentes entre si, quem forma se forma e reforma ao formar e quem é formado forma-se e forma ao ser formado. É neste sentido que ensinar não é transferir conhecimentos, conteúdos nem forrar é ação pela qual um sujeito criador dá forma, estilo ou alma a um corpo indeciso e acomodado. Não há docência sem discência, as duas se explicam e seus sujeitos, apesar das diferenças que os conotam, não se reduzem à 
condição de objeto, um do outro. Quem ensina aprende ao ensinar e quem aprende ensina ao aprender (Grifo do autor).

Dessa forma, analisa-se que, para a formação integral do indivíduo, no aspecto pedagógico, existe um processo alienante que vai além dos conteúdos dos currículos moldados e programados para promover uma "falsa formação" de cunho mecanizada, robotizada e intencional, como se existisse uma cartilha pronta e acabada, desconsiderando as particularidades, individualidades, cultura e a sociabilidade.

Para Demo (2006), o maior objetivo da cidadania é a emancipação do indivíduo, ou seja, a compreensão e atuação consciente em relação às estruturas de dominação, colocando-o como mero objeto a interesses dos grupos dominantes, sendo elas a prática adequada a uma intervenção na realidade social com o intuito de modificá-la. Assim, esse autor expõe:

Interdependência entre ensino e construção própria de conhecimento, o desenvolvimento de uma atitude questionadora inerente ao processo de pesquisar e a instrumentalização de conhecimentos pelo indivíduo nos contextos em que está inserido de modo que este possa, mais do que compreender sua realidade social, intervir e modificá-la por meio do exercício da cidadania (DEMO, 2006, p. 199).

No que diz respeito aos conteúdos escolares, trata-se, na área da Educação, de distinguir o que é essencial e secundário, o fundamental e o acessório, observação que instaura na pedagogia histórico-crítica a noção de clássico, que "[...] não se confunde com o tradicional e também não se opõe, necessariamente, ao moderno e muito menos ao atual. $\mathrm{O}$ clássico é aquilo que se firmou como fundamental, como essencial" (SAVIANI, 2000, p. 16). Na escola, segundo esse autor, o clássico é a transmissão-apropriação do saber sistematizado.

Para Fazenda (2005, p. 3), a didática é o caminho pelo qual o ensino se torna mediador interdisciplinar para o conhecimento, assim "[...] a didática é, está a caminho de ser, uma ciência e uma tecnologia que se constrói com base na teoria e na prática, em ambientes organizados de relação e comunicação intencional, nos quais se desenvolvem processos de ensino e aprendizagem para a formação do aluno.”.

Dessa forma, um docente que tenha uma boa formação pedagógica, através da didática consegue expor, instruir, demonstrar e orientar os conteúdos curriculares e os conhecimentos de sociabilidade afim de provocar a construção de conhecimento no educando.

Fazenda (1988) compreende que os recursos didáticos, como quadrode-giz, lousa interativa, entre outros, contribuem para a aproximação ou 
afastamento entre os alunos e ou professores, despertando maior ou menor interesse nas aulas, sendo, portanto, refletido nas relações sociais e no aprendizado. Assim, "[...] a relação pedagógica é um processo de interação em movimento e que se constitui de sentimentos, valores, pensamentos e experiências que fazem parte da história social de cada indivíduo e que se expressam nas relações" (FAZENDA, 1988, p. 1).

Portanto, é preciso investir na formação continuada do docente e melhorar substancialmente os salários dos professores, proporcionando o comprometimento e a formação integral do professor para que se possa chegar a uma formação integral do discente.

Para Saviani (2008a, apud PEREIRA, 2014), o currículo é um processo de construção social, realizado dentro de cada escola e ou região, consistindo em uma seleção de elementos culturais da sociedade, valorizando assim suas singularidades. O currículo deve ser construído em sala de aula, com o desenrolar das tarefas educativas e as características de discentes e docentes, atentando-se às necessidades que surgem a cada momento. Quando se elabora o currículo, percebe-se que há uma distância considerável entre o que é oficialmente prescrito e o currículo real, que objetivamente acontece na escola.

Nesse contexto, entende-se que não é possível elaborar propostas curriculares comuns em um país tão desigual e plural, como o Brasil, assim deve haver "[...] um currículo para cada região, um currículo para cada escola, quiçá, para cada classe" (SAVIANI, 2008a, p. 4, apud PEREIRA, 2014, p. 21).

Segundo Arroyo (2007, apud PEREIRA, 2014, p. 23), as propostas curriculares nacionais não podem ser conteúdos prontos que devem ser repassados para os educandos, pois essas propostas devem ser construídas de acordo com uma seleção de "[...] conhecimentos, valores, instrumentos da cultura em contextos e práticas sociais e culturais". Por isso, é identificada a preocupação em resgatar nos currículos a relação entre o conhecimento e a cultura, e não uma cartilha padronizada comum e inflexível.

Silva (2009, apud PEREIRA, 2014) expõe que o educando deve ter a compreensão da realidade em que está inserido, interpretando-a e contribuindo para sua transformação. $\mathrm{O}$ ambiente escolar tem papel fundamental para a formação e a transformação humana, que só terá cumprido seus objetivos, ao assumir uma postura ética, critica, estética, econômica e política, pois o currículo não deve ser visto como uma simples lista de conteúdo a ser aplicado.

O currículo elaborado pelo MEC e presente na BNCC para o Ensino Médio, que está em avaliação, traz uma proposta curricular comum para todo o Brasil, inflexível e acabado, como pode-se observar nas palavras do Ministro da Educação Renato Janine, "A base nacional comum curricular estabelecerá quais conteúdos e competências os alunos devem aprender em cada ano de formação 
na educação básica, bem como estabelecerá as disciplinas obrigatórias na educação básica" (BRASIL, 2015, p. 1).

A proposta da Reforma modifica o Ensino Médio com a inserção de mais carga horária de ensino e a formação técnica do aluno. A carga horária atual de 800 horas sobe para 1400 horas por ano, com curso de três anos, as aulas em tempo integral e os currículos básicos e técnicos articulados e integrados.

Embora a carga horária seja mais extensa na reforma proposta, um período maior dentro das dependências da escola pode ser muito interessante ao educando, desde que haja uma boa diversidade de tarefas e atividades, o aproveitamento das aulas com a inserção da tecnologia, entre outras inovações, distribuídas ao longo do tempo. Ou seja, a boa equação é uma divisão entre atividades curriculares e extras, menos tempo ocioso em casa ou nas ruas.

Freitas (2018) afirma que a BNCC, após ser elaborada pelo MEC sem consultar os profissionais da educação, busca aprovação do magistério. Nesse pensamento, esclarece:

No Brasil o suporte à BNCC está sendo dado por um grupo de tecnocratas e especialistas (alguns bem intencionados), organizados no Movimento pela Base, financiado pela Fundação Lemann. Há algum tempo, a Fundação Lemann vem se aproximando do Conselho Nacional de Secretários de Educação (CONSED) e da União Nacional dos Dirigentes Municipais de Educação (UNDIME) criando uma espinha dorsal que, alinhada com o MEC, cujo atual ministro foi do CONSED, constituem uma máquina de indução para a aprovação e implementação da BNCC. Como resultado, construíram uma proposta disforme e agora estão em busca do magistério para que ele a adote (FREITAS, 2018, p. $01)$.

Em 24 de julho de 2018, o Movimento pela Base (2018), divulgou um "roteiro" para os estados começarem as consultas públicas sobre a elaboração da primeira versão dos currículos estaduais. No que diz respeito ao objetivo da consulta, " [...] a (re)elaboração dos currículos em regime de colaboração com os municípios é um passo essencial para que a Base Nacional Comum Curricular (BNCC) se torne realidade nas escolas de todo o país" (MOVIMENTO PELA BASE, 2018, p. 01).

Em relação às possíveis contribuições para a reelaboração do currículo comum, o Movimento pela Base (2018), em parceria com o MEC expõe:

A ideia é que professores, gestores e a comunidade escolar possam enviar sugestões para deixar os currículos com a cara da região, atendendo às expectativas e necessidades de específicas de cada rede, e incorporando a diversidade dos municípios ao documento. Para que as 
contribuições sejam mais significativas, é preciso conhecer bem o que a BNCC determina e identificar oportunidades de melhorar o que está proposto no currículo. Seja contextualizando um objeto de conhecimento ou habilidade dentro da riqueza sociocultural da região, seja acrescentando novas competências e habilidades que fazem sentido para os alunos do estado, seja sugerindo práticas pedagógicas que podem ajudar a aprimorar o trabalho do professor (MOVIMENTO PELA BASE, 2018, p. 01).

Embora seja explanado a real necessidade de desenvolver um currículo sério e comprometido com a formação cidadã e integral, fica evidente a máscara dada à reforma, dando uma falsa ilusão de construção de um currículo que valorize os conhecimentos sociais e culturais regionais, bem como as habilidades individuais do educando, porém o currículo é já está pronto, moldado e limitado aos seus padrões predeterminados, assim:

O texto, logo no início diz a que veio (todos os grifos que se seguem são meus):

"A (re)elaboração dos currículos em regime de colaboração com os municípios é um passo essencial para que a Base Nacional Comum Curricular (BNCC) se torne realidade nas escolas de todo o país".

"A ideia é que professores, gestores e a comunidade escolar possam enviar sugestões para deixar os currículos com a cara da região."

"Para que as contribuições sejam mais significativas, é preciso conhecer bem o que a BNCC determina." (FREITAS, 2018, p. 01. Grifo do autor).

Assim, Freitas (2018) conclui que o foco principal da mobilização é pelo esforço para que a BNCC chegue até a sala de aula, "que se torne realidade em todas as escolas do país", e a "participação" está limitada a aplicar a base em sala de aula. "Reelaborar" e "dar a cara da região" é a mensagem de abertura que não sugere "participar" efetivamente da elaboração de uma base estadual curricular. A participação permitida é aquela que "dá a cara" do local à base pronta. É um convite para que o magistério coloque uma "máscara" na BNCC pronta, para que ela se pareça com a região e com suas particularidades.

A ênfase está na aplicação da base já pronta, assim, diz:

Seja contextualizando um objeto de conhecimento ou habilidade dentro da riqueza sociocultural da região, seja acrescentando novas competências e habilidades que fazem sentido para os alunos do estado, seja sugerindo práticas pedagógicas que podem ajudar a aprimorar o trabalho do professor (FREITAS, 2018, p. 02. Grifo do autor). 
Desta forma, Freitas (2018, p. 3) compreende que “[...] todas as escolhas relevantes, já foram feitas ao se montar a BNCC em Brasília. Agora, trata-se de que a pílula seja engolida: um verdadeiro desrespeito à inteligência do magistério. A isso foi reduzida a "participação" do magistério. E ainda querem dizer que a BNCC não é currículo".

O processo de implantação da Reforma do Ensino Médio, norteado pela BNCC, caracteriza-se pelo autoritarismo e a implantação de um currículo insatisfatório, sob os aspectos pedagógicos e estruturais. Assim, compete observar:

É preciso começar tudo de novo, exatamente porque uma base nacional curricular comum não deve ser currículo é que ela está condenada, pois amarrou tudo de cima para baixo. Uma base deve ser uma referência construída coletivamente, que tenha o sentido de um projeto nacional, que aponte o que entendemos todos (não apenas os empresários, suas fundações e ONGs) por ser uma "boa educação para nossas crianças e jovens". Ela deveria ter começado pelos Estados e Municípios, envolvendo aqueles que fazem a educação (FREITAS, 2018, p. 03).

Com a nova BNCC, os educadores têm a autonomia limitada, restrita a aplicação de conteúdos curriculares e pedagógicos pré-estabelecidos, tornando o processo de ensino-aprendizagem mimético, irrefletido e irrealizável. Assim, deixa em evidência que as diretrizes da BNCC educarão profissionais e cidadãos com baixo nível de conhecimentos sociais, intelectuais e profissionais e tornando-os susceptíveis a serem oprimidos pelo sistema capitalista exploratório e acumulativo.

Esse processo de "formação deficitária" é mediado pela educação, atendendo as necessidades capitalistas, que serve de instrumento de dominação e extensão da exploração da classe trabalhadora, assim é o modelo de educação que vem prevalecendo no Brasil.

Lamentavelmente, a educação brasileira, embora tenha um aparato legal que assegure qualidade, respeito à cultura local, promoção da cidadania plena, ainda atende a interesses alheios aos da própria sociedade, aos próprios anseios de desenvolvimento almejados pela sociedade igualitária e justa.

O Governo Federal, por intermédio do MEC, formulou e concluiu a BNCC do Ensino Médio de forma autoritária, sem a participação efetiva da comunidade educacional e intelectual da área. O currículo balizado pela BNCC não prestigia a formação integral e muito menos os valores regionais, culturais e sociais a que está exposto o discente, a comunidade, a própria escola. Assim, o processo de formação educacional, em seu aspecto pedagógico e curricular, não apresenta um sistema integrado e articulado com o processo ensino- 
aprendizagem, que seja capaz de preparar os jovens e adultos para a vida e para o trabalho.

Por fim, a Reforma do Ensino Médio, nos moldes da BNCC apresentada, configura um marco histórico podendo ser chamada de reestruturação capitalista intervencionista com a "modernização do antigo" no sistema educacional. Portanto, legitimando e aperfeiçoando um sistema dual na educação, uma escola para os oprimidos e outra para os opressores. Desse modo, a educação perde seus propósitos sobre o desenvolvimento humano e volta seu olhar à promoção das ideologias alienantes capitalistas, formadora de força de trabalho como meio de produção exploratória.

\section{Críticas e perspectivas}

Desde o programa de Educação para Todos, que orientou as mudanças na política educacional da América Latina e do Caribe, na década de 1990, o que se detecta é uma perspectiva de educação seletiva e minimalista para os que provavelmente vão exercer trabalho simples na vida, priorizando a educação básica e restringindo-se às "necessidades básicas de aprendizagem". Trata-se de um programa que buscou consolidar a seguinte política:

Política compensatória para a diminuição da pobreza, tentando, também, diminuir as "tensões sociais" causadas pelas políticas de ajuste e reforma estrutural, conduzidas pelo FMI e pelo BM, bem como promover uma governabilidade estável na região (MELO, 2003, p. 199).

O que se pode afirmar sobre a política educacional brasileira é que tem reiterado a tendência de apropriação privada das formas mais desenvolvidas dos conhecimentos científicos, filosóficos e artísticos produzidos pela humanidade, o que se observa, inclusive, no âmbito das reformas curriculares.

Ramos (2017) defende que, com a aplicação da BNCC, melhorará o relacionamento entre escola/professor/aluno, apresentando um currículo que permite o diálogo com o mundo juvenil, além de interligar os governos federal, estadual e municipal em relação as dificuldades encontradas para obter professores em determinadas regiões. Nesse aspecto, convém reportar:

Com a base, as universidades saberão o que têm de ensinar aos professores e as escolas saberiam o que cobrar deles. Seria possível criar uma avaliação nacional. O professor pode fazer uma prova para seguir a carreira nacional, financiada em conjunto pelos governos federal, estadual e municipal, com remunerações que hoje as cidades não são capazes de bancar sozinhas. Dependendo da nota, o professor poderá escolher se fica em seu Estado ou se vai para outro que tenha vaga. O 
governo poderá suprir as necessidades de Estados e municípios com esses profissionais. (RAMOS, 2017, p. 1)

Contrariamente a essa concepção, o coordenador Geral da Campanha Nacional pelo Direito à Educação (CNDE), Daniel Cara, acredita que as medidas criam uma cortina de fumaça para o cerne do problema, que, na verdade, vão além de meras modificações no currículo ou aumento da carga horária de estudos. Em relação a isso, compete analisar:

Essa reforma é uma falácia, porque não resolve as questões estruturais, como a formação de professores e pontos que eram demandas dos estudantes que ocuparam as escolas, como a redução do número de alunos por classe. De nada adianta ênfase em exatas ou humanidades, se o professor for mal preparado, se não houver recurso. (CARA, 2016, p. $01)$.

A flexibilização de algumas matérias: Artes, educação física, filosofia ou sociologia, deixará assim uma lacuna para que estas deixem de ser obrigatórias e sem esses conhecimentos não há formação completa de um cidadão (CARA, 2016). Além disso, pode-se avaliar:

Em nenhum lugar do mundo uma reforma dessa envergadura é colocada em prática dessa forma. $\mathrm{Na}$ Austrália se levou dois anos, na Finlândia, 10. É preciso um debate sério, é preciso ouvir professores e alunos. A MP é autoritária, permitindo que o Executivo aja como um superlegislador. Houve pressa para atender a demandas de grupos educacionais. (CARA, 2016, p. 1)

Sobre os custos da Reforma, há críticas de como o Governo a colocará em prática, se não há recurso disponível. Segundo Cara (2016, p. 1), "[...] basta olhar de perto para ver que não vai ter dinheiro para implementar mudanças como a da carga horária, especialmente quando se olha o que está sendo proposto na PEC 241, que limita os gastos nessa área".

Segundo Leão (2018, p. 12), em se tratando de perspectivas para os rumos da Educação a partir da reforma, "[...] um primeiro aspecto a considerar no debate sobre os rumos do ensino médio se refere às repercussões das transformações sociais sobre a condição juvenil brasileira que incidem diretamente sobre suas experiências escolares".

Ainda para Leão (2018), é fato que as propostas de Reforma do Ensino Médio trazem em seus "objetivos ocultos" a necessidade de atender às "novas" demandas do setor produtivo e a necessidade de melhorar a posição no ranking dos sistemas de avaliação do Ensino Médio, atendendo aos compromissos firmados com mecanismos financeiros internacionais. Porém, em meio aos 
desencontros pedagógicos e curriculares, encontram-se os sujeitos ativos que podem servir de ponto de partida sobre as questões de formação e como eles as concebem. Sobre essa questão, é ressaltado:

Talvez um bom ponto de partida nas análises das propostas em voga seja nos perguntarmos sobre como concebem os sujeitos ao qual se destina esse nível de ensino. Quem são os jovens estudantes das escolas públicas de ensino médio brasileiro? São os mesmos de 20 ou 30 anos atrás? Qual nosso olhar sobre esses sujeitos? O que conhecemos da condição juvenil brasileira contemporânea? (LEÃO, 2018, p. 12)

Mesmo nas contradições existentes entre a escola real e escola "abstrata" proposta pelo MEC, outras escolas estão se formando no Brasil e muitas pesquisas e debates fluem no sentido de uma reconstrução ou mesmo uma Contra Reforma do Ensino Médio. Sobre isso, reporta-se:

Não se trata de "partir do zero", desconsiderando as experiências acumuladas e que fazem a escola que temos. Algumas políticas que se constituíram recentemente, mesmo com suas contradições e insuficiências, indicavam o rumo de um longo processo de inovações a partir das escolas e da interlocução com a sociedade. Independentemente dos governos e suas políticas, ou apesar deles, há uma escola de ensino médio sendo produzida por docentes e estudantes em suas escolas. Olhemos em nossas pesquisas e debates para esses processos de construção da escola que temos! Seus alcances e limites! (LEÃO, 2018, p. 20)

No entendimento de Leão (2018), o Ensino Médio passa por reformulações que pouco contribuem para a emancipação da juventude, pelo contrário, afasta-os cada vez mais do protagonismo que lhes é de direito, apresentando uma proposta que não vai além da formação para a força de trabalho, isto é, deixa de lado o aprendizado para o exercício da cidadania, o desenvolvimento intelectual e a capacidade de atuar criticamente no meio onde vive o aprendiz.

Num olhar crítico sobre aspectos de formação do conhecimento pela educação e suas práticas pedagógicas, a Educação Básica encontra-se totalmente falida, na atualidade. O "sujeito fim", o educando, o alvo do ensino escola está e continuará limitado a uma formação deficitária, visto que, se não tem professores bem remunerados e qualificados, como esperar que se pode ter alunos com formação integral; e, se os currículos e as práticas pedagógicas estão moldados em uma linha de formação alienada, como ter formação integral.

$\mathrm{Na}$ verdade, a Reforma do Ensino Médio com a Base Nacional Comum Curricular vem como "disfarce" proposto pelo Governo para "salvar" o Ensino Médio do fracasso que vem se desenhando nos últimos anos, 
propondo muitas mudanças negativas sob o ponto de vista da formação do cidadão ativo de seus direitos, propondo: vantajoso ao discente por poder escolher os itinerários a seguir nos estudos, mas, por outro lado, com a Emenda Constitucional no 95/2016 (BRASIL, 2016), discorre sobre contenção de aumento de gastos, a oferta é de escolha dos sistemas de ensino; a diluição da Sociologia e Filosofia em outras disciplinas, o que pode representar o enfraquecimento da construção da postura cidadã mais ética, reflexiva e crítica diante da complexidade dos problemas, atualmente, vistos na sociedade; a retomada da visão reducionista no itinerário formativo técnico e profissionalizante, valorizando a formação técnica em detrimento da intelectual, bem como a formação cidadã; entre outras.

Para Fagiani (2018, p. 126),

A questão fundamental está em suprimir a divisão do trabalho manual e intelectual. Nessa direção a educação escolar na formação do trabalhador se torna fundamental e determinante, seja na sua aplicação, seja no seu planejamento. Uma educação que não forme o jovem trabalhador especificamente para um trabalho de forma unilateral, dependente, como um simples treinamento, mas para o trabalho totalizante, um processo de recuperação da integralidade do Ser Humano, comprometida pela divisão do trabalho e da sociedade, com desenvolvimento de forças materiais intelectuais que representa o domínio deste Ser Social sobre a natureza, possibilitando e satisfazendo seu desenvolvimento de forma omnilateralmente e independente.

Com a implantação da Reforma, por certo, a falta de equidade será ainda um entrave ao desenvolvimento da educação, uma vez que o ensino ofertado à elite do país será mais condizente com as reais bases curriculares para um ensino abrangente, contemplando mais oportunidades na vida do discente. É fato que isso implicará no crescimento ainda mais do fosso entre ricos e as classes menos favorecidas no país, sobretudo, quanto às oportunidades de escolaridade, desenvolvimento intelectual, social e profissional. Destaca-se que, no Brasil, o rendimento dos trabalhadores com ensino de nível superior é 157,18\% superior aos trabalhadores com ensino de nível médio (FAGIANI, 2018).

\section{Considerações finais}

Ao analisar a Reforma do Ensino Médio, uma BNCC que padroniza as práticas pedagógicas e limita a integração e progressão das habilidades específicas do docente, dificultando a formação integral do aluno e direcionando-o para a formação do homem produtivo, com habilidade técnica 
profissional limitada até mesmo para a adaptação e qualificação continuada, pode-se constatar que o caminho assumido pela reforma inviabiliza uma formação crítica, autônoma e emancipadora. Desta forma, estreitando as possibilidades de movimento social ao mesmo tempo que direciona o capital intelectual à elite dominadora exploratória capitalista.

A reforma do Ensino Médio não foi amplamente discutida com a comunidade escolar e intelectual. A proposta da reforma não oferece subsídios integrados e articulados em prol de uma boa gestão com infraestruturas adequadas, procedimentos técnicos e pedagógicos com potencial para uma educação integral e integrante, ou seja, trata-se de mudanças arbitrárias imposta por força de lei. Assim, percebe-se nitidamente seu caráter autoritário e o eminente fracasso na formação de jovens e adultos, dificultando assim, o exercício pleno das atividades sociais, profissionais e intelectuais.

Em suma, o sistema educacional é manipulado pela classe social burguesa capitalista, por intermédio do Governo Federal, defendendo os interesses econômicos e políticos, replicando por meio de "reformas" o sistema "dual", tendo uma educação para a classe opressora e outra para os oprimidos. Contrariamente a esse mecanismo de controle social, espera-se que a educação possibilite diminuir a desigualdade socioeconômica, melhorando a qualidade de vida do cidadão e, para isso, é necessário às escolas a imparcialidade diante dos desejos de classes, considerando as desigualdades socioeconômicas no processo pedagógico de formação, construindo assim uma educação única integral e integrante.

\section{Referências}

BRASIL. Decreto 2208 de 1997. Regulamenta o $\$ 2^{\circ}$ do art. 36 e os arts. 39 a 42 da Lei $\mathrm{n}^{\circ}$ 9.394, de 20 de dezembro de 1996, que estabelece as diretrizes e bases da educação nacional. Secretaria Geral da Presidência da República, Brasília, DF, 1997.

BRASIL. Parecer CNE/CEB n 39 de 8 de dezembro de 2004. Conselho Nacional de Educação e Conselho de Educação Básica. Aplicação do Decreto no 5.154/2004 na Educação Profissional Técnica de nível médio e no Ensino Médio. Brasília, 2004.

BRASIL. Base Nacional Comum Curricular. Ministério da Educação.

Primeira versão. Brasília: MEC/SEB, 16 de setembro de 2015.

BRASIL. Emenda constitucional $\mathbf{n}^{\circ} 95$ de 2016. Altera o Ato das

Disposições Constitucionais Transitórias, para instituir o Novo Regime Fiscal, e dá outras providências. Congresso nacional, Brasília, DF, 15 de dezembro de 2016. 
BRASIL. Lei $\mathbf{n}^{\circ} \mathbf{1 3 . 4 1 5}$, de 16 de fevereiro de 2017. Secretaria Geral da Presidência da República. Lei da reforma do ensino médio. Brasília, DF, 2017a.

BRASIL. Portaria n ${ }^{\circ}$ 727, de 13 de junho de 2017.Diário Oficial da União, Brasília, DF, 2017b.

BRASIL. Matrizes de Referência. Ministério da Educação, Brasília, DF, agosto de 2017, 2017c. Disponível em: http://portal.inep.gov.br/educacaobasica/encceja/matrizes-de-referencia. Acesso em: 18 set. 2017, .

CARA, D. 5 Polêmicas sobre a nova reforma do Ensino Médio. Site Último Segundo, p. 01, 24 de setembro de 2016. Disponível em: https://ultimosegundo.ig.com.br/educacao/2016-09-24/reforma-do-ensinomedio.html. Acesso em: set. 2018.

DEMO, P. Pesquisa: princípio científico e educativo. 12. ed. São Paulo: Cortez, 2006.

FAGIANI, C. C. Brasil e Portugal: qual a formação do jovem trabalhador no século XXI? Uberlândia, MG. Navegando Publicações, 2018.

FAZENDA, I. C. A. Didática e Interdisciplinaridade. Resenha: PEREIRA, L., P. 9. Edição, Papirus, PUC, Campinas, SP, 2005. (1998) .v. 1. p. 192.

Disponível em:

https://www5.pucsp.br/gepi/downloads/pdf_resenhas_profa_ivani/didatica_ e_interdisciplinaridade.pdf. Acesso em: set. 2018.

FAZENDA, I. C. A. et al. Um desafio para a didática: experiências, vivências, pesquisas. São Paulo: Loyola, 1988.

FREIRE, P. Pedagogia da Autonomia: Saberes Necessários à Prática Educativa. São Paulo, SP, Paz e Terra, 1996.

FREITAS, L. C. Avaliação Educacional: Uma BNCC à procura do magistério. Blog do Freitas, p. 01. Campinas, SP, 26 de agosto 2018.

Disponível em: https://avaliacaoeducacional.com/2018/08/26/uma-bncc-aprocura-do-magisterio/. Acesso em: 22 de setembro de 2018.

LEÃO, G. O que os Jovens Podem Esperar da Reforma do Ensino Médio Brasileiro? Vol. no 34, Educação em Revista, Belo Horizonte, MG, agosto de 2018. Disponível em: http://www.scielo.br/pdf/edur/v34/1982-6621-edur-34e177494.pdf. Acesso em: 22 setembro de 2018. 


\section{MACHADO, L. C. Gestão dos Processos Formativos na Educação}

Básica. Montes Claros, MG. Editora UNIMONTES, 2018. Disponível em: http://nead.uesc.br/arquivos/pedagogia/gestao_dos_processos_formativos/ material_apoio/

modulo_gestao_dos_processos_formativos_na_edu_basica.pdf. Acesso em: 17 set. 2018.

MELO, A. A. S. A mundialização da educação: o projeto neoliberal de sociedade e educação no Brasil e na Venezuela. Tese (Doutorado em Educação) - Faculdade de Educação, Universidade Estadual de Campinas, Campinas, SP, 2003.

MOVIMENTO PELA BASE (2018). Implementação da BNCC. Portal Movimento pela Base, 24 de julho de 2018. Disponível em:

http://movimentopelabase.org.br/acontece/bncc-comecam-as-consultaspublicas-sobre-primeira-versao-dos-curriculos-estaduais/. Acesso em: 11 set. 2018.

PEREIRA, P. O Currículo e as Práticas Pedagógicas. Sociedade cultural e educacional de Itapeva, faculdade de ciências sociais e agrárias de Itapeva. Itapeva, SP, dezembro de 2014. Disponível em: http:/ / fait.revista.inf.br/imagens_arquivos/arquivos_destaque/myLjgW5XRw u601I_2015-2-5-14-23-30.pdf. Acesso em: set. de 2018.

RAMOS, M. N. Pode haver um apagão generalizado de professores. Revista Época, p. 01, 12 de junho de 2017. Disponível em: https://epoca.globo.com/ideias/noticia/2015/10/mozart-neves-ramos-podehaver-um-apagao-generalizado-de-professores.html. Acesso em: set. 2018.

RUIZ, A. I. A Reforma do Ensino Médio. Confetam Cut, p. 01, Sinpro-DF, 11 de janeiro de 2017. Disponível em: http://www.confetam.com.br/artigos/areforma-do-ensino-medio-f961/. Acesso em: set. 2018.

SAVIANI, D. Pedagogia Histórico-Crítica: primeiras aproximações. 7. ed. Campinas, SP. Autores Associados, 2000.

TEIXEIRA, R. F. B.; LEÃO, G. M. C.; DOMINGUES, H. P.; ROLIN, E. C. Concepções de Itinerários Formativos a partir da Resolução cne/ceb n ${ }^{\circ}$ 06/2012 e da Lei no 13.415/2017. In: XIII CONGRESSO NACIONAL DE EDUCAÇÃO 2017, Anais Eletrônicos... Curitiba, PR, (Educare).31 de ago. de 2017. Disponível em: http://educere.bruc.com.br/arquivo/pdf2017/27280_14159.pdf. Acesso em: set. 2018. 